\title{
An Analysis of English Business Letters from the Perspective of Interpersonal Function
}

\author{
Bo $\mathrm{Xu}^{1}$ \\ ${ }^{1}$ School of Foreign Languages, Leshan Normal University, China \\ Correspondence: Bo Xu, School of Foreign Languages, Leshan Normal University, Binhe Road 778\#, Shizhong \\ District, Leshan, Sichuan Province, China. Tel: 86-0833-2185269. E-mail: marty_xu@hotmail.com
}

Received: March 15, 2012 Accepted: March 28, 2012 Online Published: July 1, 2012

doi:10.5539/elt.v5n7p75 URL: http://dx.doi.org/10.5539/elt.v5n7p75

\begin{abstract}
The Purpose of the present study is to find out the features of English business letters. Halliday's systemic functional linguistics is used as the theoretical framework, mainly, interpersonal fucntion. The English business letter (EBL) is an important written text used for international business communication and it has its own features of text. This paper explores the interpersonal function of EBL in terms of mood, modality, interaction and negotiation and finds that EBL has its unique interpersonal features.
\end{abstract}

Keywords: English Business Letter, interpersonal function, mood, modality

\section{Introduction}

Communication has always been highly regarded in commercial circles. In line with the means of communication, business communication can be generally divided into two types: oral communication and written communication. Indeed, written business communication by means of business letters plays a very vital role in establishing and maintaining business relationships both within a firm and with external contacts.

Nowadays English business letter Texts (EBLTs) are indispensible in international trade. A growing number of people use EBLTs in business transaction. Universities and colleges in China offer the course of EBLTs writing to train students' EBL writing skill. To master the interpersonal features of EBLT is very beneficial for those who learn or use EBLTs.

The Purpose of the current paper is to find out the unique features of English business letters from the perspecitve of interpersonal function. Halliday's Systemic Functional Linguistics is employed as the theoretical framework, mainly, interpersonal function (Halliday, 2000). In the paper, the qualitative analysis is the major research method adopted for the study with a quantitative analysis as a supplement.

The English business letter (EBL) is an important written text used for international business communication and it has its own features of text (Chen Dongchun, 2003). Based on the core theory of Systemic Functional Linguistics, i.e. interpersonal function, the paper makes a interpersonal function analysis of the features of English Business Letter Text (EBLT). EBLTs have the salient feature of courtesy and consideration. In this paper, only body part of EBLT is analyzed in terms of mood, modality, interaction and negotiation. The corpora of the paper are composed of nine types of English business letter which are most frequently used in business transaction (16 EBLs are omitted). The corpora of the paper are selected from EBL textbooks both at home and abroad.

\section{Literature Review}

Many scholars both at home and abroad have conducted researches on English business letters. In China, Wang Xinguo (1997), Li Xuansong (1997), Chen Dongchun (2003), Li Ming (2004), Xu Ju (2004) and Li Junru (2006) conduct researches on EBLTs from the perspectives of linguistic features, textual structure, stylistic characteristics and genre analysis. Liu Jianfu (2004) explores one of the most important functions of language: phatic communion. He Wei \& Pang Yunlin make a study of 30 English business letters communicating bad news, in order to reveal the linguistic devices realizing the interpersonal function (He Wei \& Pang Yunlin, 2008).

Gimenez (2000) investigates whether the spoken nature of e-mail messages has already started to affect business written communication. He makes an analysis in respect of the register and context of the language and at the style used in commercial electronic mail. Leila Barbara et al do a survey of how English is used for various communication purposes in the Brazilian business setting, namely, different types of business organizations 
(Barbara, 1996).

Carla Vergaro (2002) conducts a research on discourse strategies in Italian and English money chasing letters. Carla Vergaro (2004) describes a contrastive study on rhetorical differences between Italian and English sales promotion letters. Bargiela-Chiappini \& Harris (1996) expound requests and status in business correspondence.

The previous studies on EBLTs, both at home and abroad, mainly focus on genre, lexical features, linguistic features, phatic communion. Therefore, it is necessary to analyze the EBLT from the perspective of interpersonal function.

\section{Mood, Modality, Interaction and Negotiation in EBLTs Embodying Feature of Courtesy and Consideration}

One of the main purposes of language communication is to interact with other people: to establish and maintain appropriate social links with them. In practice, employees and practitioners use EBLTs to exchange meanings. When an EBL is composed, courtesy and consideration should be taken into consideration. This paper will probe into how courtesy and consideration of EBLTs realized under the heading of mood, modality and interaction and negotiation between the writer and the receiver.

\subsection{Mood in EBLTS}

In order to understand the role relationships in EBLTs, sixteen letters are analyzed in terms of mood. Based on classification of mood types put forward by Thompson (Thompson, 2000, p. 40) and Halliday (Halliday, 2000, p. 85), an analysis of mood components is made by the author of this paper at clause level to decide types of mood used in EBLTs. Table 1 illustrates the result in terms of frequency of each mood type in the sixteen samples.

As is shown in Table 1, there are altogether 134 ranking clauses (excluding embedded clauses). It is obvious to find out that declaratives take up $96 \%$, imperatives $2 \%$, Yes/no interrogatives $2 \%$ and no exclamatives are found in EBLTs.

Table 1. Mood in the sixteen EBLTs

\begin{tabular}{|c|c|c|c|c|c|c|c|c|c|c|c|c|c|c|c|c|c|c|}
\hline \multicolumn{19}{|c|}{ Mood (ranking clauses only) } \\
\hline Mood Types & L1 & $\mathrm{L} 2$ & L3 & L4 & L5 & L6 & L7 & L8 & L9 & L10 & L11 & L12 & L13 & L14 & L15 & L16 & total & $\%$ \\
\hline Declaratives & 10 & 6 & 9 & 6 & 8 & 8 & 8 & 8 & 8 & 9 & 6 & 7 & 8 & 11 & 10 & 7 & 129 & $96 \%$ \\
\hline Exclamatives & 0 & 0 & 0 & 0 & 0 & 0 & 0 & 0 & 0 & 0 & 0 & 0 & 0 & 0 & 0 & 0 & 0 & 0 \\
\hline Imperatives & 0 & 0 & 1 & 0 & 1 & 0 & 0 & 0 & 0 & 0 & 1 & 0 & 0 & 0 & 0 & 0 & 3 & $2 \%$ \\
\hline $\begin{array}{l}\text { Yes/no } \\
\text { interrogatives }\end{array}$ & 0 & 0 & 0 & 0 & 0 & 0 & 0 & 0 & 1 & 0 & 0 & 0 & 0 & 1 & 0 & 0 & 2 & $2 \%$ \\
\hline Total & 10 & 6 & 10 & 6 & 9 & 8 & 8 & 8 & 9 & 9 & 7 & 7 & 8 & 12 & 10 & 7 & 134 & $100 \%$ \\
\hline
\end{tabular}

Note: L 1 means Letter 1; L2 means Letter 2 ...

Most of mood classes are declaratives (96\%) (see Table 1) which provide information for the letter receiver. The function of declaratives in EBLTs goes beyond its unmarked function to give information. They work together to provide goods-\&-services to the receiver (Eggins, 2004). They contribute to the interpersonal meaning in EBLTs in that the final product provides the receiver with courtesy and consideration with a carrier of their emotion, and with ideological enlightenment. It also signals the relationship between the writer and the receiver: the writer is active and takes the initiative in the communication, while the receiver is the recipient of the letter.

Mood plays a special role in carrying out the interpersonal functions of the clause. In order to understand what this role is, the meanings expressed by the Subject and Finite should be examined, and then to see how they work together as Mood. One sentence is chosen from Sales Promotion Letter to an Old Customer.

(1) A current price list is also enclosed. (From Letter 3)

Mood in declarative clause could be examined in terms of the exchange going on between the two parties. One way of doing this is by examining the kind of response that the letter receiver can make to the information being given (since the response will show us how the letter receiver is interpreting the purpose of the letter writer's message). From this perspective, the letter writer has put up for negotiation something about "price", not about shipment.

The Subject expresses the entity that the writer wants to make responsible for the validity of the proposition being advanced in the clause. The receiver can then confirm, reject, query or qualify the validity by repeating or amending the Finite, but the Subject must remain the same: if that is altered, the exchange has moved on to a new proposition (Thompson, 2000, p. 46). 
If the Subject is the entity on which the validity of the clause rests, what is the meaning of the Finite? To some extent, the answer has begun to emerge from the discussion of Subject: the Finite makes it possible to negotiate about the validity of the proposition. The Subject can be seen as non-negotiable as long as the current proposition remains in play. Through the Finite, the writer signals three basic kinds of "claims" about the validity of the proposition, each of which in principle is open to confirmation or rejection by the receiver (Thompson, 2000, p. 46):

a. For what time in relation to that of speaking the proposition is valid (tense).

b. Whether the proposition is about positive or negative validity (polarity).

c. To what extent the proposition is valid (modality).

The following examples illustrate each of the above claims being contested or amended in turn:

(2) "I thought it was a firm offer. But it is not."

(3) "You know what I mean."” "No, I don't, as a matter of fact."

(4) "Look out- he might scratch you." "Too late - he has."

Now, the examination goes back to example (1) again.

\section{A current price list is also enclosed.}

It can be understood as follows: the validity of the information the writer is giving the receiver rests on the receiver's accepting that both sides are referring to "price"; the validity the writer claims for the information is that it is valid for something present (not past or future tense), it is absolutely valid (not modalised) and that it is positively valid (not negative); and the information the writer wants to give the receiver about "price" is "enclosed" in the letter.

The rest of the clauses are imperatives and interrogatives, both of them play the role of demand, demanding either information or goods-\&-services. They take up a small proportion in the total (imperatives account for $2 \%$ and interrogatives account for $2 \%$ ), but they still count. Besides giving information, the writer also demands something from the receiver. As the letter writer is not communicating with the receiver face to face, there should be ways to involve the receiver in the letter. When the letter writer gives information, the receiver is expected to acknowledge the information. While the letter writer asks a question, the receiver is expected to answer the question. As the letter writer gives a command, the receiver is expected to comply with the command. If the receiver does not follow the command, the exchange will be halted. If he/she follows the letter, he/she is complying with the letter writer's demand (Thompson, 2000).

According to Eggins (Eggins, 2004, p. 177), demands for goods and services are typically realized by imperatives. Imperatives are the unmarked mood type used to make a command. Imperative mood accounts for $3 \%$ in the sixteen EBLTs (see table 1). Imperatives are used in EBLTs to demand goods- \&-services. Furthermore, the using of word "please" indicates the writer's courtesy and politeness for the receiver. Examples are shown as follows:

(5) Please fill in the enclosed Despatch Form and return it to us with the consignment and commercial invoices. (From Letter 11)

(6) Please use the order form enclosed. (From Letter 3)

(7) Please note that we have quoted our most favorable price and are unable to entertain any counter-offer. (From Letter 5)

The interrogative mood realizes the speech role of question. Yes/no interrogatives mood take up $2 \%$ in the sixteen EBLTs. Yes/no interrogative mood is employed to give goods- \&-services. In addition, the employment of "could you" and "would you" not only inquires the receiver and gets the receiver's consent, but also incarnates the writer's courtesy to the receiver. Moreover, through using Yes/no interrogatives mood, politeness and euphemism is achieved in EBLTs. Examples are given as follows:

(8) Could you allow me a further 60 days to clear my account, and draw a new bill on me, with interest of, say 6\% added for the extension of time? (From Letter 9)

(9) Would you please fill out the enclosed claims form and return it to us, with a letter confirming acceptance of the compensation we have offered? (From Letter 14)

\subsection{Modality in EBLTS}

The Finite expresses not only tense but also modality. In order to understand more fully how modality works, we need to return to the distinction in speech roles. 
Thompson (Thompson, 2000, p. 57) considers that if the commodity being exchanged is information, the modality relates to how valid the information is in terms of probability (how likely it is to be true) or usuality (how frequent it is true). Some of the basic points on the probability scale are: possible/probable/certain; on the usuality scale, they include: sometimes/often/always. If, on the other hand, the commodity is goods-\&-services, the modality relates to how confident the writer can be in the eventual success of the exchange. In commands, this concerns the degree of obligation on the other person to carry out the command (the scale for the demanded goods- $\&$-services includes: permissible/advisable/obligatory), while in offers it concerns the degree of willingness or inclination of the writer to fulfill the offer (the writer may signal: ability/willingness/determination).

The sixteen EBLTs are classified into probability, usuality, obligation and inclination in terms of clause. Boldface is the lexicon showing the scale which can be classified into the four categories. Through the classification of modality above, for the sixteen EBLTs, a table is drawn to demonstrate the percentage of the four categories (see Table 2).

Table 2. Modality in the sixteen EBLTs

\begin{tabular}{lll}
\hline Type & Clause No. & Percentage \\
\hline Probability & 11 & $27 \%$ \\
Usuality & 1 & $3 \%$ \\
Obligation & 7 & $17 \%$ \\
Inclination & 21 & $53 \%$ \\
\hline
\end{tabular}

As can be seen from Table 2, it is apparent that probability accounts for $27 \%$ in the sixteen EBLTs; usuality accounts for $3 \%$ in the sixteen EBLTs; obligation takes up $17 \%$ in the sixteen EBLTs and inclination takes up $53 \%$ in the sixteen EBLTs.

Inclination accounts for 53\%, which signifies the commodity exchanged in EBLTs is mostly realized by finite modal operator which belongs to proposal (goods-\&-services). EBLTs signal the willingness, keenness and determination of the participating party. In addition, 53\% of inclination in EBLTs indicates that the writer adopts words like "will" to convey his or her willingness so that courtesy is realized in EBLTs. The writer uses inclination to signal willingness or determination of his/her side. For example:

(10) This letter will be handed to you by Mr. Frank Chadwick, our senior representative, who will be spending much of his time during June and July in the Far East. [...] he will need than anyone else we know. We shall regard as a personal favor any help you give Mr. Chadwick and will always be very happy to reciprocate. (From Letter 1)

As bold face words are used in Letter 1, the writer employs "will" or "shall" throughout the whole letter to express his or her willingness which incarnate the courtesy of the writer.

Since probability takes up $27 \%$, the commodity exchanged in EBLTs is also realized. The indications of probability in EBLTs are usually expressed with finite modal operator and modal adjunct (such as possible, probably, certain). Usuality takes up 3\%. Probability and usuality used in EBLTs is to exchange information between the two sides. Obligation (taking up 17\%) shows the degree of the writer to demand for goods- $\&$-services.

By using four categories of media: probability, usuality, obligation and inclination, the EBLT writer exchanges his/her information and goods-\&-services with the receiver.

\subsection{Interaction and Negotiation between the Writer and the Receiver}

When interacting with another person, the writer will inevitably enact one of the speech roles: anything he/she says will be intended and interpreted as a statement, question, command or offer (Thompson, 2000). By acting out a role, he/she is at the same time creating a corresponding role for the other person (even if the other person does not in turn carry out that role): in asking a question, for instance, the writer creates the role of answerer for the other person. However, the writer may also project a role onto himself or the other person by the way he/she talks about them (ibid.).

Personal pronouns are usually used to tell interpersonal relationships between or among the individuals involved in interaction (Zhang Yanjun, 2006, p. 112). EBL writers can use different kinds of pronouns to indicate their attitudes and relationships to readers in their texts, presenting statements subjectively, interactively, or objectively. Personal pronouns in the basic grammatical distinctions are those used to indicate first or second or third person. $I$ indicates the individual who utters the text; you refers to the individual addressed in the present instance of text; the third person pronouns (he, she, it, they), unlike the first or second pronoun, refer to the other party or parties in the 
situation but not the participants in the speech event (ibid.). Person system in the sixteen EBLTs is demonstrated in Table 3 .

Table 3. Frequency of personal pronouns in the sixteen EBLTs

\begin{tabular}{|c|c|c|c|c|c|c|c|c|c|c|c|c|c|c|}
\hline \multirow{2}{*}{ Pronoun } & \multicolumn{5}{|c|}{ First-person } & \multicolumn{2}{|c|}{ Second-person } & \multicolumn{7}{|c|}{ Third-person } \\
\hline & $\mathrm{I}$ & me & my & we & us & you & your & he & his & she & her & it & its & they \\
\hline No. & 13 & 7 & 6 & 45 & 16 & 48 & 25 & 4 & 3 & 0 & 0 & 5 & 0 & 2 \\
\hline
\end{tabular}

As is shown in Table 3, the most frequently used pronoun is "you" (48 times). Then "we" (45 times) ranks the second place. "Your" (25 times) ranks the third place. "Us" (16 times) ranks the fourth place in sixteen EBLTs.

Since courtesy and consideration lays emphasis on You-attitude rather than We-attitude, the most-frequently-used second person pronoun in the sixteen EBLTs evinces that the writer emphasizes You-attitude which keeps the receiver's request, needs, desires as well as his or her feelings in mind. By doing so, courtesy is incarnated in the EBLTs.

In a broad sense, by using second person pronoun, the writer emphasizes the reader's interest and concerns and he/she pays much more attention to "you" and "your" and de-emphasizes "we" and "our". But it is more than a matter of just using second person pronouns. It is an attitude of mind to place the letter receiver in the center of things. At times, it involves being friendly and treating people in the way they like to be treated. Sometimes, it involves skillfully handling people with carefully chosen words to make a desired impression. The writer is negotiating with the receiver. In this way, courtesy and consideration of EBLTs is realized via frequent use of second person pronoun.

Moreover, first person pronoun "we" is also constantly seen in EBLTs. The first person pronoun "we" also signifies the spirit of cooperative attitude and sincerity. In this way, the receiver may feel pleased when reading the letter.

\section{Conclusion: Appraisal of Interpersonal Function in EBLTs}

As for mood, different mood types realize different interpersonal meaning in EBLTs. Declarative clauses provide goods-\&-services for the receiver through statement. It indicates that the relationship between the writer and the receiver is that of the carrier of emotion and the receiver of emotion. Imperatives and interrogatives create a sense of dialogue in the form of command, arousing the receiver's attention and evoking their thinking. They are used to shorten the distance or bridge the gap between the writer and the receiver. The writer carefully selects mood types to convey courtesy and consideration.

Generally speaking,the most frequently used types are that of inclination and probability because EBLTs convey statement to imply whether it is possible to accept the writer's proposal, imparting opinion to the receiver. The commodity exchanged in EBLTs is mostly achieved by finite modal operator which belongs to proposal (goods-\&-services). EBLTs mostly embody the willingness, keenness and determination of the participating party. Letter writers adopt words like "will" to convey his or her willingness or wish to the other side so that courtesy can be achieved in EBLTs.

In terms of person system in EBLTs, the frequent use of second-person pronoun states clearly that the writer emphasizes You-attitude which visualizes the receiver's needs, problems, and possible reactions to the writing and puts himself/herself in the reader's position. Such thoughtfulness is essential to establish good interpersonal relations between the reader and the writer. Consequently, consideration of EBLTs is realized via frequent employment of second person pronoun.

\section{References}

Bargiela-Chiappini F., \& S. J. Harris. (1996). Requests and Status in Business Correspondence. Journal of Pragmatics, 26, 635-662. http://dx.doi.org/10.1016/0378-2166(96)89191-0

Chen Dongchun. (2003). Genre Analysis and Writing Strategies of English Business Letters. Foreign Laugages Teaching, 2, 52-56.

Eggins, S. (2004). An Introduction to Systemic Functional Linguistic (2 ${ }^{\text {nd }}$ Edition). New York: Continuum International Publishing Group.

Gimenez, J. C. (2000). Business E-mail Communication: Some Emerging Tendencies in Register. English for Specific Purposes, 19, 237-251. http://dx.doi.org/10.1016/S0889-4906(98)00030-1 
Halliday, M. A. K. (2000). An Introduction to Functional Grammar ( $2^{\text {nd }}$ edition). London: Edward Arnold/ Beijing: Foreign Language Teaching and Research Press.

He Wei, \& Pang Yunlin. (2008). The Interpersonal Meaning of English Business Letters Communicating Bad News. Journal of Guangdong Univeristy of Foreign Studies, 1, 39-43.

Leila Barbara M., et al. (1996). A Survey of Communication Patterns in the Brazilian Business Context. English for Specific Purposes, 15, 57-71. http://dx.doi.org/10.1016/0889-4906(95)00026-7

Li Xuansong. (1997). Genre Analysis and Business Text. Journal of Foreign Languages, 2, 26-29.

Liu Jianfu. (2004). Phatic Comuninion in English Business Letters. Journal of Guangdong Univeristy of Foreign Studies, 4, 29-32.

Li Ming. (2004). On the Linguistic and Textual Features of Business English. Journal of Guangdong Univeristy of Foreign Studies, 2, 32-37.

Thompson, G. (2000). Introducing Functional Grammar. London: Edward Arnold.

Thompson, G. (2008). Introducing Functional Grammar (2 ${ }^{\text {nd }}$ Edition). London: Hodder Arnold.

Vergaro, C. (2002). Discourse Strategies in Italian and English Money Chasing Letters. Journal of Pragmatics, 34, 1211-1233. http://dx.doi.org/10.1016/S0378-2166(02)00046-2

Vergaro, C. (2004). Discourse Strategies of Italian and English Sales Promotion Letters. English for Specific Purposes, 23, 181-207.

Wang Xinguo. (1997). Stytistic Features of English Business Letters. Journal of Sichuan International Studies University, 3, 64-72.

Xu Ju. (2004). Genre Analysis of Business English Letters. Journal of Xian International Studies University, 1, 26-29.

Zhang Yanjun. (2006). A Study of Academic Paper from the Perspective of Interpersonal Function. Qingdao: Ocean University of China Press.

\section{Author}

Bo Xu (1979-), male, was born in Shiyan, Hubei Province, and he earned his Master of Arts in Guangxi University in 2009 and now is the lecturer of School of Foreign Languages, Leshan Normal University. His academic field includes English for Specific Purpose, Discourse Analysis and Systemic Functional Linguistics. 